\title{
Deciphering the phylogenetic relationships among rhizobia nodulating chickpea: A Review
}

\author{
Pooja Suneja $^{1}$, Surjit Singh Dudeja ${ }^{2}$, Pushpa Dahiya ${ }^{3}$ \\ ${ }^{1}$ Department of Microbiology, Department of Botany3, M.D.U., Rohtak, India. \\ ${ }^{2}$ Department of Bio \& Nanotechnology, G. J. U. of Science \& Technology, Hisar, India.
}

\begin{tabular}{l} 
ARTICLE INFO \\
\hline Article history: \\
Received on: $17 / 02 / 2016$ \\
Revised on: $01 / 04 / 2016$ \\
Accepted on: $03 / 05 / 2016$ \\
Available online: $21 / 06 / 2016$ \\
\hline Key words: \\
Chickpea, Mesorhizobium, \\
16S rDNA, Polyphasic.
\end{tabular}

\begin{abstract}
Rhizobia, Gram-negative bacilli are capable of fixing atmospheric nitrogen in symbiotic association with leguminous roots. These were classified earlier on the basis of morphology, physiology and biochemical characters. But with the dawn of new era of molecular approaches, various evolutionary chronometers have led to re-classification of these soil bacteria. Chickpea is the most important leguminous crop of arid and semi-arid regions of world. The rhizobia strains which nodulate chickpea exhibit genomic heterogeneity. The various molecular techniques such as DNA-DNA hybridization, RAPD-PCR, REP (repetitive extragenic palindrome) PCR, ERIC (enterobacterial repetitive intergeneric consensus) and BOX element or the finger printing of rhizobia genomes using ribosomal genes (16S, 23S or 16S-23S inter generic spacer - IGS), DAPD (direct amplified polymorphic DNA) are regularly used to identify, differentiate and characterize rhizobia infecting chickpea. Though, the ribosomal RNA is conserved but it exhibits variability in some of the domains and this makes ribosomal gene sequence (16S and 23S DNA) an optimum choice for deducing phylogenetic and evolutionary relationship among chickpea rhizobia. But 16S r RNA sequence is not sufficient enough to distinguish the strains of one species or even closely related species. The additional genes like nod genes, nif genes, glutamine synthetase and other housekeeping genes have also been used in combination to 16S rRNA to study the evolutionary relationship among these rhizobia. This has led to proper taxonomy and systematics of the rhizobia group, with the description of new genera up to the level of species and sub species. The chickpea rhizobia have been grouped under genus Mesorhizobium with several species such as M. ciceri, M. mediterraneum, M amorphae, M. tianshanense, M. loti, M. huakuii, M. opportunistum and M. muleiense.
\end{abstract}

\section{INTRODUCTION}

Legumes possess seeds with high protein content therefore, require high supply of nitrogen. Nitrogen, an essential element for plant, though present in environment at approximate level of $78 \%$, is still not accessible to plants. The extensive use of chemical fertilizers to get high yield is not only expensive, but also a threat to the environmental balance and contributes to global warming. Biological nitrogen fixation fulfils plants' requirements of nitrogen by converting atmospheric nitro gen into usable form i.e. ammonia. Legume-rhizobial symbiotic association in root nodule is a well-known $\mathrm{N}_{2}$-fixing system.

\footnotetext{
* Corresponding Author

Pooja Suneja, Assistant Professor, Department of Microbiology, Maharshi Dayanand University, Rohtak-124001Haryana, India

Mobile No.: +919812028424, Email: poojapavit@gmail.com
}

Chickpea (Cicer arietinum L.) is an important leguminous crop of Indian subcontinent and being the second most widely grown crop of world. Production of chickpea in world has increased and reached upto $11.6 \mathrm{mt}$ in 2011 and around 70\% contributor is India being the largest chickpea producer as well as consumer in the world (http://faostat3.fao.org). There is a large number of rhizobia present in soil, resembling each other in morphological and cultural characteristics but form nodules on very specific hosts. The legumes can be promiscuous or restrictive host to these rhizobia. Promiscuous host can be nodulated by different groups of rhizobia i.e. broad host range rhizobia and even in a single nodule more than one type of rhizobia have been reported. As rhizobia have different plant hosts and occupy diverse niches which has led to their diversification [1].

This may have resulted due to their geographical isolation from a common ancestor. Restrictive host can be nodulated by only specific rhizobia and not by broad host range rhizobia [2]. 
Chickpea is one of the restrictive host among legumes, can be nodulated by members of genus Mesorhizobium, described by Jarvis et al. in 1997[3]. Now, various studies have revealed that several species of this genus can nodulate chickpea [4].

Initially, rhizobia were identified on the basis of various phenotypic characters: morphology, physiology/metabolism, serological analysis, ecology. Earlier a large range of biochemical and metabolic tests including intrinsic antibiotic resistance (IAR) were also used to differentiate Rhizobium species [5-8]. Further, techniques like heavy metal tolerance, bacteriophage typing and polyacrylamide gel electrophoresis of total cellular proteins (SDSPAGE), multilocus enzymes has been successfully used for studying the diversity and classification of the rhizobia [9-12]. Discrimination of rhizobia into strains, species, sub-species or biotypes depends upon the methodology being used.

The native rhizobial populations were analysed using serological techniques. Members of a population exhibiting antibody-antigen reaction were assigned to a serogroup and can be considered similar, if not identical [13, 14]. In 1979, Gaur and Sen [15] performed the cross-inoculation experiments on chickpea rhizobia and found that they were able to nodulate only the original host plant Cicer arietinum, indicating that these rhizobia represent a separate inoculation group. It was also observed that these bacteria do not show any serological cross-reaction with known rhizobia [16]. However, serology, the most commonly used method in sixties and seventies had certain limitations. It can identify only those fields isolates which cross react with antisera raised against laboratory strains. Thus, indigenous bacteria that do not cross react serologically must be classed in a single group that potentially is quite diverse and can include the majority of the isolates. It was very cumbrous in cases of large number of strains.

Until the discovery of molecular methods, the microbial taxonomist had to rely on phenetic system of classification which classifies organisms on the basis of their phenotypic characters. After the proposal of Carl Woese and George Fox, 1977 [17] to use small subunit nucleotide sequence to assess the evolutionary relationship among organisms focus for characterizing rhizobia has been shifted from phenetic to phylogenetic approaches as these are much more rapid and unambiguous to study heterogeneity of rhizobial strains particularly based on recent advances in DNA fingerprinting methods based on the Polymerase Chain Reaction (PCR). RAPD-PCR, PCR amplification of REP (repetitive extragenic palindrome), ERIC (enterobacterial repetitive intergeneric consensus) and BOX element or the finger printing of rhizobial genomes using ribosomal genes $(16 \mathrm{~S}, 23 \mathrm{~S}$ or $16 \mathrm{~S}-23 \mathrm{~S}$ inter generic spacer - IGS) are routinely used to identify, differentiate and characterize rhizobia [18-30]. Alternatively, variation can also be estimated by RFLP analysis of $16 \mathrm{~S}$ r DNA sequence amplified by PCR. Variations in $16 \mathrm{~S}$ rRNA genes can be estimated by direct sequencing of the product after PCR amplification [31,32].

The rRNA gene sequencing has certain limitations as it uses only single gene which can be overcome by taking into account more than one gene. Multilocus sequence typing technique consists of sequencing of several different housekeeping genes from an organism and comparing the sequences with the sequence of same gene from the different strains of the organism. Genes other than the ribosomal RNA genes have also been analysed, such as nod genes, nod $D, \operatorname{nod} C$, nif $D K$, nif $H$, glutamine synthetase (GSI GSII), recA and $a t p D$. This has led to proper taxonomy and systematics of the group of rhizobia nodulating legumes with the description of the new genera up to the level of species and sub species [33-35].

Whole genome sequencing or full genome sequencing determines the complete DNA sequence of an organism. The comparison of sequence of single gene or multiple genes gives valuable information about taxonomy as well as phylogeny. But single gene analysis provides only limited information, while multiple genes may have been subjected to horizontal gene transfer which could lead to incorrect information. Whole genome sequence analysis gives detailed and complete information about the organism.

Till date, 113 symbiotic nodulating bacterial species have been identified in 11 genera of $\alpha$-proteobacteria and 3 genera of $\beta$ proteobacteria: Azorhizobium, Bradyrhizobium, Aminobacter, Ensifer, Devosia, Mesorhizobium, Methylobacterium, Ochrobactrum, Phyllobacterium, Rhizobium, Microvirga, Shinella and Burkholderia, Cupriavidus, Herbaspirillum (http://www.rhizobia.co.nz/taxonomy/rhizbia) Most of the species are in the genera Rhizobium, Bradyrhizobium, Mesorhizobium and Ensifer [36, 37]. A number of molecular techniques have been used to characterize chickpea rhizobia which are discussed below.

\section{Genotypic and Molecular methods as taxonomic tools}

Different genotypic and molecular analysis methods such as DNA-DNA hybridization, GC ratios, DNA profiling methods using PCR such as RAPD-PCR, rep (repetitive extragenic palindrome)-PCR,ERIC-PCR, RFLP ,16S rRNA genes,23S rRNA genes or $16 \mathrm{~S}-23 \mathrm{~S}$ intergenic spacer-IGS were used to study the phylogenetic diversity of chickpea rhizobia (Table1 \& 2).

\subsection{DNA-DNA Hybridization}

DNA-DNA Hybridization helps to differentiate organisms and reveals the subtle differences between the genome of two organisms. The hybridization values greater than $70 \%$ are recommended as evidence that two isolates belong to same species. Values of $25 \%$ or more are needed to check whether the organisms under consideration belong to same genera. It is used as complement to ssu rRNA gene sequencing. The DNA-DNA hybridization techniques showed that chickpea rhizobia had low levels of homology (less than 17\%) to Rhizobium and Bradyrhizobium species [38]. The genetic and phylogenetic relationships of type strain (A-1BS) of $M$. tianshanense and the type or reference strains for M.loti, M.huakuii, M.ciceri, M. mediterraneum and cluster U was also analysed by DNA-DNA hybridization using southern-blotting method. The type strain of M. tianshanense formed a separate DNA-homologous group [39]. Though, this method provides useful information but it has certain 
limitations as the facilities needed are not always available in all the laboratories. Moreover, it is laborious, expensive and results are difficult to reproduce [40].

DNA-DNA relatedness of chickpea rhizobial strain CCBAU 83963(T) varied from 15.28-50.97\% when compared with type strains of genus Mesorhizobium. Even the SDS-PAGE of whole-cell soluble proteins of all the three strains i.e. CCBAU 83963(T), CCBAU 83939 and CCBAU 83908 isolated from alkaline soils of China, were also found to be different from Mesorhizobium. Upon the analysis of available data, three novel rhizobial strains were characterise as Mesorhizobium muleiense sp.nov [41].

\section{2. $G+C$ content}

$\mathrm{GC}$ content refers to the percentage of nitrogen bases that is guanine and cytosine on a DNA molecule. GC- content of whole genome or a specific fragment of DNA or RNA can be taken into account. It varies in different organisms, values as low as $17 \%$ to as high as $80 \%$. The guanine and cytosine are bound by three hydrogen bonds as a result the DNA with high GC-content is more stable. The fragments with high GC-content have high melting temperature and it helps in determining the annealing temperature of primers thus helping in standardising the PCR reactions. The GC content of different chickpea rhizobia was determined by highperformance liquid chromatography, it was found to be $64 \mathrm{~mol} \%$ in case of representative strain and strains UPM-Ca7T and IC2091 had 63 mol\% GC content [38].

\subsection{DNA Profiling}

Several methods are used to generate the DNA profiles for genotypic analysis between rhizobial strains. The commonly employed methods to study the phylogenetic relationship among chickpea rhizobia are: repetitive extragenic palindromic (repPCR), restriction fragment length polymorphism (RFLP), ribotyping, plasmid profiles, amplified fragment length polymorphism (AFLP), ARDRA and random amplified polymorphic DNA (RAPD).

\subsubsection{Rep-PCR}

It is based on the presence of highly conserved repetitive DNA sequences interspersed randomly around the bacterial chromosome in multiple copies. It is used to discriminate bacteria up to strain level. Three families of repetitive sequences have been identified: i) REP (repetitive extragenomic palindromic) elements ii) ERIC (enterobacterial repetitive intergenic consensus) iii) BOX elements [42]. Specific primers are used to amplify the regions located between REP, ERIC or BOX elements and amplified fragments are resolved on gel electrophoresis to obtain specific pattern

\subsubsection{ITS-PCR}

Intergenic transcribed Spacer-PCR is used to identify bacterial strains and based on the polymorphism within the ITS of $16 \mathrm{~S}-23 \mathrm{~S}$.

\subsubsection{RFLP}

It is based on the presence of restriction sites within a bacterial genome. Different types of profiles are generated which further depends upon the type of restriction enzymes used and bacterial group under consideration. Sometimes the complex profiles are generated which makes it difficult to compare. Ribotyping, AFLP and ARDRA are derivatives of RFLP.

\subsubsection{AFLP}

It is based on the digestion of genomic DNA with one or two restriction enzymes, ligation with specific adaptors and selective PCR amplification of the resulting fragments.

\subsubsection{ARDRA}

Ribosomal DNA is digested using different restriction enzymes and all the profiles are combined to get a specific pattern.

\subsubsection{RAPD}

It is a type of polymerase chain reaction in which a single primer called as arbitrary primer anneals and amplify the complementary DNA strand. The amplification of DNA occurs randomly and length of PCR product varies from $100 \mathrm{bp}$ to $3 \mathrm{~kb}$. Band number varies from 1 to 15 . Banding pattern generated by the separation of PCR products on agarose gel electrophoresis is termed as 'RAPD fingerprint' or 'RAPD profile'. Although, it has advantage of using many arbitrary primers for large population but it also has certain limitations as it is not necessary that products of equal size may represent the identical regions. Moreover, this method is also sensitive to selection of primers and laboratory conditions to carry out the PCR reactions.

\subsection{S rRNA sequence based phylogeny}

Sequencing of $16 \mathrm{~S}$ rRNA has revolutionised the bacterial taxonomy and it has given a whole new set of parameters to identify, characterize and classify bacteria [43]. Traditional system of classification was based on various phenotypic characteristics which describe the morphology, physiology, biochemical properties, antigenic properties and serological properties. But now the modern taxonomists rely more on the organisms' DNA analysis. 16S rRNA gene is present in all bacteria and archaea, codes for ribosomal RNA which makes up the part of small subunit of ribosome i.e. it is universally distributed and functionally constant. This give advantage of identify and classify bacteria (prokaryotes) in a given sample, separating them from eukaryotic DNA which has 18S rRNA gene (Fungi, Algae, Protista, Plant and Animals). 16S rRNA gene is preferred over the other unique bacterial genes as it is relatively short $(1.5 \mathrm{~kb})$ making it faster and cheaper for sequencing. It has both conserved as well as hypervariable regions. The Ribosomal RNA is conserved due to its structural constraints in ribosomes and due to existence of variability in some domains renders ribosomal gene sequence of $16 \mathrm{~S}$ and $23 \mathrm{~S}$ subunits as very good choices for deducing phylogenetic and evolutionary relationship among bacteria. A large and constantly growing database of $16 \mathrm{~S}$ rRNA 
gene sequences exists. However, the amount of variation present in the $16 \mathrm{~S}$ rRNA is sometime insufficient to discriminate the closely related species and even the strains of same species. The relationship of taxa in phylogenetic trees may be distorted by horizontal gene transfer of $16 \mathrm{~S}$ rRNA gene [44, 45].

\subsection{Polyphasic approaches to characterise Mesorhizobium}

A polyphasic approach involving genotypic, chemotaxonomic and phenotypic methods for characterization and determination of taxonomy of microorganisms is preferred now days, as it helps in reclassification of microbes and placing them into correct genera and species. Native rhizobial population nodulating chickpea, exhibiting heterogeneity, has been reported at different locations with the presence of different serotypes, biotypes or bio groups using simple serological or antibiotic resistance techniques and using PCR amplifications [22,23,38,46$56]$ These genome profiling techniques offer a convenient way to choose the right representative strains, from each genomic cluster, for further taxonomic studies such as multilocus sequence analysis (MLSA), DNA-DNA hybridization which (because of high costs) are usually carried out with only a few strains. Modern polyphasic bacterial taxonomy is based on the integration of different kinds of data, i.e., phenotypic, genomic, and phylogenetic.

\section{Diversity of Chickpea Rhizobia 3.1 Using 16S r RNA-RFLP}

Since the early nineties, the phenotypic and genotypic diversity of chickpea rhizobia was studied using biochemical and molecular methods which included auxanographic test using carbon sources, antibiotic resistance assay, salt and $\mathrm{pH}$ tolerance, DNA homology, G+C content, RFLP of $16 \mathrm{~S}$ intergenic spacer rRNA gene, partial 16S rRNA sequencing and total 16S rRNA sequence analysis [38,46]. Information obtained from these techniques confirmed that the chickpea rhizobia cannot be grouped with any of the previously described bacterial species and the rhizobia nodulating chickpea were placed under the genus Mesorhizobium.

The biodiversity of rhizobial strains nodulating chickpea grown in different regions of Morocco was studied using physiological, metabolic as well as molecular characters. Phenotypic characters included the resistance to antibiotics and heavy metals, tolerance to saline conditions, extreme temperatures and $\mathrm{pH}$, ability to utilize 49 carbohydrate sources and symbiotic traits. The molecular analysis was done by restriction fragment length polymorphism (RFLP) of PCR-amplified 16S rDNAs and comparing it with reference strains. The rhizobia were found to be phenotypically and genetically diverse and most of them belonged to genus Mesorhizobium. However, some strains had 16S rRNA genes similar to Sinorhizobium and displayed different auxanographic characteristics as compared to Mesorhizobium. This was the first report of nodulation of chickpea by members of Sinorhizobium genus [51]. Both phenotypic and genotypic markers were used to determine the diversity of chickpea rhizobia grown in various areas of Tunisia. Restriction fragment length polymorphisms (RFLPs) of PCR-amplified 16S rDNA of these isolates were compared with those of reference strains. The results showed that out of total 48 isolates, 40 isolates were similar to Mesorhizobium ciceri and 8 isolates were assigned to Mesorhizobium mediterraneum [52]. Diversity of chickpea rhizobia (110) from Portugal and Madeira Island was assessed using 16S rRNA gene. Large diversity was found to exist between these isolates and they were grouped into four main clusters. Of the total isolates, $33 \%$ were grouped along with specific chickpea rhizobia i.e. M.ciceri (cluster B) and M.mediterraneum (cluster D). The other isolates which were present in cluster D showed similarity with M.huakuii and M. Amorphae [53]. A study was carried out in Iran aimed to characterize the chickpea rhizobia so as to obtain the effective inoculants as fertilizers. The morphological, physiological and biochemical studies were done with 120 isolates and 82 were able to nodulate the chickpea. On the basis of biochemical test they were clustered into six groups and representatives of each group was subjected to16 rRNA sequencing. Results showed that isolates C-22, C-35, C-35A, C-97 and C-105 were similar to $M$. ciceri while the isolate SWRI-9 showed similarity to M. Mediterraneum [52]. A total of 28 rhizobial isolates of chickpea from peninsular and northern India were phenotypically and genotypically characterized. These isolates were compared with two reference strains M.ciceri TAL620 and M.mediterraneum UPM-Ca142. Three clusters at $67 \%$ similarity were obtained by 16 S DNA-RFLP. Results showed that $46 \%$ these isolates were grouped with M.loti and others were similar to M.cicei and M.mediterraneum [54].

\subsection{Using RFLP-16S rRNA along with DAPD/RAPD}

Chickpea rhizobia were isolated from nodules of chickpea plants grown in Portuguese soils [50]. On the basis of 16S-rDNA sequencing technique these rhizobia showed similarity to $M$. ciceri and $M$. mediterraneum but few of the isolates were close to $M$. loti or $M$. tianshanense and some formed a separate clade. The direct amplified polymorphic DNA (DAPD) analysis also supported the $16 \mathrm{~S}$ - based phylogeny suggesting that the DAPD analysis can also be used as tool to study the evolutionary relationship.

The phenotypic characters of chickpea rhizobia from five Portuguese soils were studied by IAR profiles and SDS-PAGE analysis of proteins while the molecular methods used were RFLP$16 \mathrm{~S}$ rDNA, direct amplified polymorphic DNA (DAPD) fingerprinting. A dendrogram was generated using the software BioNumerics. Clusters generated by IAR profiles were similar to those obtained by molecular methods. The study suggested that the DAPD and IAR profiles can be used in discriminating the strains of same species [56].

Similarly, the chickpea rhizobia growing in Spain soils were also characterise by $879 \mathrm{~F}-\mathrm{RAPD}$ fingerprinting and $16 \mathrm{~S}$ rDNA sequencing. The results showed the presence of four groups by 879 F-RAPD fingerprinting. The representative strain from each group belonged to genus Mesorhizobium as identified by $16 \mathrm{~S}$ rDNA sequencing [57]. 
Table 1: Molecular techniques used to characterize mesorhizobia

\begin{tabular}{|c|c|c|c|}
\hline S.No. & $\begin{array}{c}\text { Techniques used } \\
\end{array}$ & Place of Origin & Reference \\
\hline 1. & $\begin{array}{l}\text { DNA homology } \\
\text { G+C content } \\
\text { RFLP of } 16 S \text { - intergenic spacer rRNA gene } \\
\text { Partial } 16 S \text { rRNA sequencing }\end{array}$ & France & {$[38]$} \\
\hline 2. & $\begin{array}{l}\text { DNA-DNA relatedness analysis } \\
\text { RFLP of 16S rDNA IGS } \\
\text { Total 16S rRNA sequence analysis }\end{array}$ & France & {$[46]$} \\
\hline 3. & Plasmid profiles and restriction analysis of nif $\mathrm{H}$ gene & Portugal & [48] \\
\hline 4. & RFLP-16S rDNA & Morocco & [51] \\
\hline 5. & 16S-rDNA,DAPD & Portugal & [50] \\
\hline 6. & 16S-rDNA,DAPD & Portugal & [56] \\
\hline 7. & 16S-rDNA,879F-RAPD fingerprinting & Spain & [57] \\
\hline 8. & 16S-rDNA,ERIC & India & {$[22]$} \\
\hline 9. & symbiotic genes ( $n$ ifH and nodC) and $16 \mathrm{~S}$ rRNA gene & Portugal & [58] \\
\hline 10. & 16S-rDNA & Portugal & [53] \\
\hline 11. & $16 \mathrm{~S}$ rRNA gene, ITS region and the five core genes $a t p D, d n a J, g \ln A, g y r B$, and $r e c A$. & Portugal & [65] \\
\hline 12. & DNA-DNA relatedness & China & [41] \\
\hline 13. & 16S rDNA-RFLP & India & [55] \\
\hline 14. & 16S rDNA-RFLP and simple sequence repeats (SSR) & India & [27] \\
\hline 15. & $\begin{array}{l}16 \mathrm{~S} \text { rRNA, Five housekeeping genes: atpD, } \operatorname{dnaJ}, g \ln A A, g y r B \text { and } r e c A \text {, three } \\
\text { symbiosis genes: nifH, nifK, nod }\end{array}$ & India & [67] \\
\hline 16. & RAPD profiles, 16S-RFLP analysis and sequencing of the $r r s, r e c A, g \ln I I$ and $n o d C$ & Canary Islands & [68] \\
\hline 17. & Repetitive element sequence-based (rep)-PCR, and 16S rRNA sequences & Iran & [28] \\
\hline & $\begin{array}{l}\text { Mesorhizobium ciceri } \\
\text { Mesorhizobium mediterraneum } \\
\text { Mesorhizobium amorphae } \\
\text { Mesorhizobium tianshanense } \\
\text { Mesorhizobium loti } \\
\text { Mesorhizobium huakuii } \\
\text { Mesorhizobium opportunistum } \\
\text { Mesorhizobium muleiense }\end{array}$ & $\begin{array}{l}{[38]} \\
{[46]} \\
{[57]} \\
{[57]} \\
{[58]} \\
{[53]} \\
{[65]} \\
{[41]}\end{array}$ & \\
\hline
\end{tabular}

\subsection{Use of both 16S rRNA and ERIC Primers}

The molecular diversity of rhizobia nodulating two chickpea cultivars (ICC4948 and ICC5003) was studied using ERIC-PCR. Eight rhizobial genotypes were trapped by chickpea cultivars. Two rhizobial isolates LN 707b and LN7007 isolated from cvs. ICC4948 and ICC5003 respectively were characterized by amplification and sequencing of $16 \mathrm{~S}$ rRNA gene. They showed more than 98\% (LN707b) and 99\% (LN7007) sequence similarity with Mesorhizobium sp. [22]. Chickpea plants with nodules were collected from 32 different farmers' fields representing different chickpea varieties of eight districts of Haryana state (India) to determine the diversity of mesorhizobia. This Molecular diversity of 50 Mesorhizobium population was assessed by PCR amplified ERIC profiles as well as RFLP of 16S rDNA and considerable diversity of Mesorhizobium was observed in Haryana soils [23].

\subsection{Use of Symbiotic genes and 16S rRNA gene}

Chickpea rhizobia were isolated from three different geographical locations of southern Portugal and genetic characterization was done by plasmid profiles and restriction analysis of the nif $H$ gene. The symbiotic efficiency was also determined. They were found to be significantly different in terms of their symbiotic efficiency [48]. The Mesorhizobium nodulating chickpea in Spain and Portugal were analysed using the 16S rRNA gene, 16S-23S intergenic spacer (ITS), and symbiotic genes nodC and nifH. They were identified as M.amporphae and M.tianshanense on the basis of 16S rRNA gene. The type strains of these isolated from different legumes (Glycyrrhiza pallidiflora and Amorpha fruticosa) in China were not capable of nodulating chickpea and symbiotic genes diverted from chickpea isolates. Results indicated that during coevolution along with other legumes they might have acquired the symbiotic genes. It was proposed that the new infrasubspecific division i.e. biovar ciceri should be incorporated with $M$. amorphae and $M$. tianshanense [57]. The Mesorhizobium species other than M. ciceri and M. mediterraneum can also effectively nodulate chickpea though its being a restrictive host.

The 21 rhizobia were isolated from nodules of chickpea grown in Portuguese soils. Their phylogeny was studied on the basis of symbiotic genes (nifH and nodC) and 16S rRNA gene. When the phylogenies based on 16S rRNA gene were compared with symbiotic genes it was found that lateral transfer of symbiotic genes has occurred. Further it revealed chickpea as a nonpromiscous host, nodulated by different species sharing common symbiosis genes [56]. The symbiotic genes nodC and nifH of M. muleiense shared high degree of similarity with nodC and nifH of M. mediterraneum and M. ciceri [59]. 


\subsection{Using simple sequence repeats along with 16S rDNA-RFLP}

Nineteen rhizobia isolated from chickpea nodules were phenotypically characterised as different strains of Mesorhizobium, Rhizobium, Bradyrhizobium, and Agrobacterium. Their molecular diversity was assessed on the basis of simple sequence repeats (SSR) and 16S rDNA-RFLP markers. Results revealed the presence of 20 SSR loci of M.ciceri which were distributed across the other rhizobial genome. The results of $16 \mathrm{~S}$ rDNA showed that the nucleotide variables were present at 20 different positions [27].

\subsection{Use of repetitive element sequence-based (rep)-PCR, and 16S rRNA sequences}

PCR genomic fingerprinting of forty-five isolates from root nodule of chickpea grown in Iran were characterized by repetitive element sequence-based (rep)-PCR (124-127bp ERICelement and 154-bp BOX-element) and 16S rRNA sequences. Based on ERIC and BOX-PCR, strains were classified into six clusters (A-F) at the $75 \%$ similarity level. These six clusters at $85 \%$ similarity level were further divided into several sub-groups. One isolate from each cluster i.e. total six isolates (M1, A1, G1, R1, D1, B1) were selected for 16S rRNA sequence analysis. The isolate M1 was close to M. ciceri, B1 to A. tumefaciens and G1, $\mathrm{R} 1, \mathrm{~A} 1$ and $\mathrm{D} 1$ were found to be closely related to $M$. mediterraneum [28].

\section{Phylogeny based on other genes (Housekeeping and symbiosis genes) (Multi-gene sequence analysis) Origin of Symbiovar}

Initially, Rhizobium leguminosarum was the only one species of legume root - nodule bacteria. Around 50 years later, it was found that these isolates were having different host range and were able to nodulate only specific host [60]. This criteria further made the basis of their classification and named according to the host e.g. R. leguminosarum (pea rhizobium), $R$. meliloti (sweet clover rhizobium), R.trifoli (clover rhizobium) and $R$. japonicum (Japanese rhizobium nodulating soybean). For many years there was no change in rhizobial taxonomy but in 1982 genus Bradyrhizobium was proposed for slow growing rhizobia and merged $R$. leguminosarum, $R$. trifoli and $R$. phaseoli into a single species $i$. $e$. biovars ( strains of same species having different physiological and biochemical characters) of a single species [61]. But now with the passage of time and availability of genomic data, has given a clearer understanding of biovars. The specificity of host is determined by the 'nodulation genes' which are part of accessory, or shell, genome present on plasmids [62]. In contrast, stable taxonomy is given by the core genes present on chromosomes and involved in housekeeping processes. This explains that bacteria of same species having same core genes can have different host specificity due to presence of different accessory genomes. These accessory genomes harbour by bacteria provide many important properties above and beyond nodulation e.g. term 'pathovar' describes the host range of plant pathogen, 'serovar' describes the antigenic properties of cell surface of bacterium. Similarly, the term 'symbiotic variety' or 'symbiovar' is more precise than biovar [63]. Since then the use of term symbiovar is emphasized and the information on occurrence of symbiovars in different rhizobial species has been compiled.

The 16S rDNA also has limitations as it cannot discriminate closely related species that's why analysis of core genome will help in better understanding of phylogenetic relationship among mesorhizobia. Two currently used core genes are: $r e c A$ and $a t p D$. Along with core genes, the auxiliary or accessory gene involved in symbiosis also aid in proper taxonomy of Mesorhizobium. The commonly studied symbiotic genes are $\operatorname{nodD}$, nodA, nodC and nifH [64]. The multilocus sequence analysis approach was used to study the symbiovars of Mesorhizobium nodulating chickpea [65]. It included 16S rRNA gene, ITS region and the five core genes atpD, dnaJ, glnA, $g y r B$, and recA. The phylogenetic analyses of core genes and their comparison with nodC supported the presence of one new chickpea Mesorhizobium genospecies and one new symbiovar, $M$. opportunistum sv. Ciceri.

Human domestication of legumes may have resulted in selection of specific rhizobial lineage which was best suited for nodulation. It has also been observed that rare legumes are nodulated by more specific rhizobia [66]. Domestication of chickpea too have impact on symbiosis. It reduces genetic diversity in cultivated gene pool of chickpea (Cicer arietinum) as compared with wild species (C. reticulatum and $C$. bijugum).The 4 accessions of $C$. arietinum and 3 accessions of each of $C$. reticulatum and C. bijugum were selected. DNA was isolated from their nodules to find out the phylogenetic similarity among mesorhizobia. For this 9 genes (16S rRNA, Five housekeeping genes: atpD, dnaJ, gln $A, \operatorname{gyr} B$ and $r e c A$, three symbiosis genes: nifH, nifK, nod) were selected based on sequence diversity. The similarities among mesorhizobia ranged from $92 \%$ to $100 \%$ in case of four housekeeping genes ( $a t p D, d n a J, g \ln A$ and $r e c A$ ) and $98 \%$ to $100 \%$ in case of $16 \mathrm{~S}$ rRNA sequences. The nifH gene sequences were also having $96-100 \%$ similarity. Due to high level of similarities, these genes were not included for further studies. The remaining three genes, one housekeeping $(\mathrm{gyr} B)$ and two symbiosis genes (nifK and nod) displayed diversity among the different strains of M.Ciceri. These genes were having 86-100\% similarities in 143 sequences and revealed that the sequences from C. reticulatum were more diverse as compared to $C$. arietinum. So domestication of chickpea has negatively affected the symbiosis [67]. In Canary Islands, rhizobia nodulating chickpea were isolated and characterise using RAPD profiles, 16S-RFLP analysis and sequencing of the rrs, recA, glnII and nodC genes. Nine biotypes were observed on the basis of 16S-RFLP and predominant ribotypes were found to be clustered with reference strains of $M$. ciceri, M. tianshanense, M. mettallidurans, M. opportunistum, $M$. caraganae, M. tamadayense, M. gobiense. The results revealed that the effective symbiosis occurs due to combination of core and symbiotic genes and $C$. canariense appears to be a promiscuous legume as it is nodulated by several species and symbiotypes [68]. 

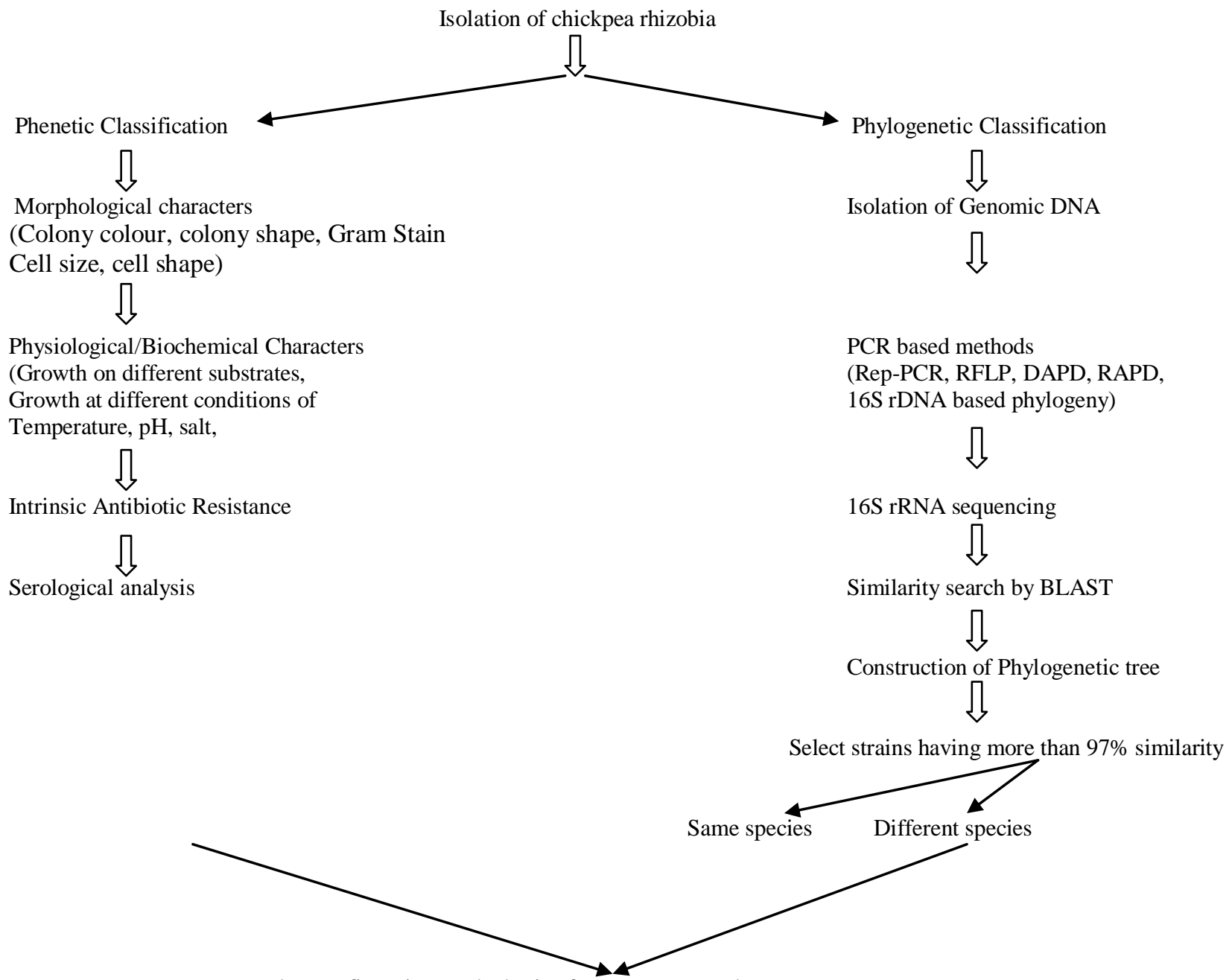

Further confirmation on the basis of core genome and accessory genome

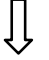

Complete analysis using the results of both phenotypic as well as genotypic markers

(Polyphasic approach)

Finally confirmation by Whole Genome Sequence Analysis

\section{Whole Genome Sequence}

Whole genome sequencing discloses the complete DNA sequence of a microorganism and helps to find the variations between/within species. The entire genome cannot be sequenced in one go, therefore it is broken into small pieces, each short "piece" is then sequenced using prevalent methods to assimilate the data for further integration to join larger pieces \& unfold the entire genome. Either whole-genome shotgun method or clone-by-clone approach is used for sequencing. The clone-by-clone method is slow while whole-genome shotgun method is fast.

The classification of mesorhizobia on the basis of single gene or multiple genes might not give the clear picture of its evolution. Sometimes conserved genes also undergo deletions, mutations, duplication, recombination and lateral gene transfer which results in genetic diversity among strains of same species e.g. the genome size of 20 strains of E.coli varies from 4.6 to $5.5 \mathrm{Mb}$. It means the microbial genome is dynamic rather than static [68]. The complete genome sequence of around 31 rhizobia were annotated till June 2013 and it is available in public database (www.ncbi.nlm.nih.gov).

The genome of M.ciceri Ca181, isolated from root nodules of chickpea grown in Haryana, India, has been sequenced. About 12 billion sequences have been generated by 454pyrosequence, $1.2 \mathrm{~GB}$ by Solexa-illumina and $4,000 \mathrm{~Kb}$ by Sanger Sequencing (http://www.icar.org.in/files/ICAR-News-\%20AprilJune\%202012.pdf)

The whole genome sequence of chickpea rhizobia nodulating wild and domesticated varieties of chickpea was done to characterize the chickpea mesorhizobia. Metagenomic DNA sequences from 95 root nodules out of 1,800 root nodules from 
two wild varieties ( $C$. reticulatum and $C$. echinospermum) and one cultivated ( $C$. arietinum) grown in India shown the presence of $M$. mediterraneum which is known to nodulate chickpea and $M$. plurifarium which was earlier isolated from tropical legumes. This suggests that the domestication of chickpea has led to parallel shifts in bacterial genome structure and $M$. pluriarium strains acquired symbiosis genes from $M$. mediterraneum, have adjusted to tropical Indian soil [69].

\section{CONCLUSION}

Mesorhizobium is the least studied rhizobia, various phenotypic and genomic methods have been used to explore their diversity. Most of the characterisation has been carried out using 16S rRNA gene based phylogeny. Of recently people have been studying the core genome and accessory genome of chickpea mesorhizobia. In case of mesorhizobia the symbiotic genes are present on chromosomal symbiosis islands and rarely in plasmids. Earlier the genome sequencing was labour intensive and expensive but with passage of time, cost has decreased and even high throughout next-generation sequencing methods are available. The availability of large number of genome facilitates the comparison of whole genome sequence of new isolates (http://img.doe.gov/cgi-bin/w/main.cgi). Genome sequencing helps in deciphering of core genome as well as complete insight into the symbiotic genes. But there are some limitations to this also therefore a polyphasic approach should be used to characterize the mesorhizobia. Taxonomic distribution should not only be based on single parameter. For accurate taxonomic positioning, all the parameters phenotypic, chemotaxonomic and genome sequence as well should be taken into consideration. On the basis of polyphasic approaches used genus Mesorhizobium presently consists of 29 rhizobia species and 1 non-rhizobial species. The species of Mesorhizobium which can nodulate chickpea includes: $M$. ciceri, M. mediterraneum, M. amorphae, M. tianshanense, M. loti, M.huakuii, M. opportunistum, M.muleiense.

\section{CONFLICT OF INTEREST}

The authors declare that they have no conflict of interest in the publication.

\section{REFERENCES}

1. Martinez- Romero E, Caballero-Mellado J. Rhizobium phylogenies and bacterial genetic diversity. Critical Review in Plant Science.1996; 15: 113-140.

2. Broughton WJ, Perret X. Genealogy of legume-Rhizobium symbiosis. Current Opinion in Plant Biology .1999; 2: 305-311.

3. Jarvis B D W, Van Berkum P, Chen W X, Nour S M, Fernandez M P, Cleyet-Marel J C, Gillis M. Transfer of Rhizobium loti, Rhizobium huakuii, Rhizobium ciceri, Rhizobium mediterraneum, and Rhizobium tianshanense to Mesorhizobium gen nov. International Journal of Systematic Bacteriology.1997;47:895-898.

4. Laranjo M, Alexandre A, Oliveira S. Legume growth-promoting rhizobia: An overview on the Mesorhizobium genus. Micrbiological Research. 2014; 169: 2-17.
5. Graham P H. Selective medium for growth of Rhizobium. Journal of Applied Microbiology. 1969; 17: 769-770.

6. Josey D P, Beynon J L, Johnston A W B, Beringer J E. Strain identification in Rhizobium using intrinsic antibiotic resistance. Journal of Applied Bacteriology. 1979; 46: 343-350.

7. van Rossum D V, Schuurmans F P, Gillis M, Huyotcha A, Verseveld H W V, Stouthamer A H, Boogerd F. Genetic and phenotypic analysis of Bradyrhizobium strain nodulating peanut (Arachis hypogaea L.) roots. Applied and Environment Microbiology.1995; 61: 1599-1609.

8. Chaudhary P, Khurana A L, Dudeja S S. Heterogeneity of rhizobia isolated from chickpea nodulation variants. Indian Journal of Microbiology. 2002; 42: 195-199.

9. Noel K D, Brill W J. Diversity and dynamics of indigenous Rhizobium japonicum populations. Applied and Environment Microbiology. 1980; 40(5): 931-938.

10. Pinero D, Martinez E, Selander R K. Genetic diversity and relationships among isolates of Rhizobium leguminosarum bv. phaseoli. Applied and Environment Microbiology. 1988; 55: 2825 2832.

11. Moreira F M S, Gillis M, Pot B, Kersters K, Franco A A. Characterization of rhizobia isolated from different divergence groups of tropical leguminosae by comparative polyacrylamide gel electrophoresis of their total proteins. System and Applied Microbiology. 1993; 16: 135-146.

12. Leung K, Strain S R, de-Bruijin F J, Bottomley P J. Genotypic and phenotypic comparison of chromosomal types within an indigenous soil population of Rhizobium leguminosarum bv. Trifolii. Applied and Environment Microbiology. 1994b; 60(2): 416-426.

13. Vincent J M, Humphrey B. Taxonomically significant group antigens in Rhizobium. Journal of General Microbiology.1970; 63: 379-382.

14. Dadarwal K R, Prabha S, Tauro, P. Efficiency and antigenic characteristics of green Gram (Vigna radiata bv. aureus) rhizobia. Indian Journal of Experimental Biology.1979; 17: 668-670.

15. Gaur YD, Sen AN. Cross inoculation group specificity in CicerRhizobium symbiosis. New Phytologist. 1979; 83: 745-754.

16. Kingsley M T, Bohlool B. Characterization of Rhizobium sp. (Cicer arietinum $L$.) by immunofluorescence, immunodiffusion and intrinsic antibiotic resistance. Canadian Journal of Microbiology. 1983; 29: 518-526.

17. Woese C, Fox G. Phylogenetic structure of the prokaryotic domain: the primary kingdoms. Procedings of National Academy of Sciences of the United States of America. 1977; 74(11): 5088-5090.

18. Laguerre G, Louvrier P, Allard M R ,Amarger N. Compatibility of rhizobial genotypes within natural populations of Rhizobium leguminosarum bv. viciae for nodulation of host legumes. Applied and Environment Microbiology.2003; 69: 2276-2283.

19. Sikora S., Redzepovic S. Genotypic characterisation of indigenous soybean rhizobia by PCR-RFLP of $16 \mathrm{~S}$ rDNA, rep-PCR and RAPD analysis. Food Technology and Biotechnology. 2003; 41: 61-67.

20. Moschetti G, Peluso A, Protopapa A, Anastasio M, Pepe O, Defez R. Use of nodulation pattern, stress tolerance, nodC gene amplification, RAPD-PCR and RFLP-16S rDNA analysis to discriminate genotypes of Rhizobium leguminosarum biovar viciae. System and Applied Microbiology. 1995; 28: 619-631.

21. Blazinkov M, Sikora S, Uher D, Macesic D, Redzepovic, S. Genotypic characterisation of indigenous Rhizobium leguminosarum bv. viciae field population in Croatia. Agriculturae Conspectus Scientificus. 2007; 72: 153-158.

22. Dudeja S S, Singh P C. High and low nodulation in relation to molecular diversity of chickpea mesorhizobia in Indian soils. Archives of Agronomy and Soil Science. 2008; 54: 109-120.

23. Nandwani R, Dudeja S S. Molecular diversity of a native mesorhizobial population nodulating chickpea (Cicer arietinum L.) in Indian soils. Journal of Basic Microbiology, 2009; 49(5):463-70.

24. El-Akhal M R, Rincon A, Mourabit N E, Pueyo J J, Barrijal S. Phenotypic and genotypic characterizations of rhizobia isolated from root nodules of peanut (Arachis hypogaea L.) grown in Moroccan soils. Journal of Basic Microbiology. 2009; 49(5):415-25. 
25. Elboutahiri N, Thami-Alami1 I, Zaid E, Udupa S M. Genotypic characterization of indigenous Sinorhizobium meliloti and Rhizobium sullae by rep-PCR, RAPD and ARDRA analyses. African Journal of Biotechnology. 2009; 8(6): 979-985.

26. Rashid M H, Sattar M A, Uddin M I, Young J P W. Molecular characterization of symbiotic root nodulating rhizobia isolated from lentil (Lens culinaris Medik.). Electronoic Journal Environment, Agriculture and Food Chemistrty. 2009; 8(8): 602-612.

27. Yadav A, Singh A L, Rai G K, Singh M. Assessment of molecular diversity in chickpea (Cicer arietinum L.) rhizobia and structural analysis of $16 \mathrm{~S}$ rDNA sequences from Mesorhizobium ciceri . Polish Journal of Microbiology. 2013; 62(3): 253-262.

28. Rouhrazi K, Khodakaramian G.Phenotypiv and genotypic diversity of root-nodulating bacteria isolated from chickpea (Cicer arietinum L.) in Iran.Annals of Microbiology. 2015 ; 65:2219-2227.

29. Gnat S, Małek W, Oleńska E, Trościańczyk A, Wdowiak-Wróbel S, Kalita M, Wójcik M Insight into the genomic diversity and relationship of Astragalus glycyphyllos symbionts by RAPD, ERICPCR, and AFLP fingerprinting. Journal of Applied Genetics.2015; 56:551-554 DOI 10.1007/s13353-015-0285-6.

30. Lin T, Lin L, Zhang F.Review on Molecular Typing Methods of Pathogens.Open journal of medical microbiology. 2014; 4 :147-152.

31. Yang J K, Zhang W T, Yuan T Y, Zhou J C. Genotypic characteristics of the rrn operon and genome of indigenous soybean bradyrhizobia in cropping zones of China. Canadian Journal of Microbiology. 2006; 52(10): 968-976.

32. Yang C, Yang J, Li Y, Zhou J. Genetic diversity of root-nodulating bacteria isolated from pea (Pisum sativum) in subtropical regions of China. Science in China Series C-Life Science. 2008; 51: 854-862.

33. Zézé A, Mutch L A, Young J P. Direct amplification of nodD from community DNA reveals the genetic diversity of Rhizobium leguminosarum in soil. Environment Microbiology. 2001;3(6):363-70.

34. Mutch L A, Young J P. Diversity and specificity of Rhizobium leguminosarum biovar viciae on wild and cultivated legumes. Molecular Ecology. 2004; 13(8): 2435-2444.

35. Ribeiro R A, Barcellos F G, Thompson F L, Hungria M. Multilocus sequence analysis of Brazilian Rhizobium microsymbionts of common bean (Phaseolus vulgaris $L$.) reveals unexpected taxonomic diversity. Research in Microbiology. 2009; 160(4): 297-306.

36. Weir B S. The current taxonomy of rhizobia. New Zealand rhizobia webstie. (http://www.rhizobia.co.nz/taxonomy/rhizobia.html). Last updated: 14 September, 2011.

37. Weir B S. The current taxonomy of rhizobia. New Zealand rhizobia webstie. (http://www.rhizobia.co.nz/taxonomy/rhizobia.html). Last updated: 10 April, 2012.

38. Nour S M, Cleyet-Marel J C, Beck D, Effosse A, Fernandez M P. Genotypic and phenotypic diversity of Rhizobium isolated from chickpea (Cicer arietinum L.). Canadian Journal of Microbiology.1994; 40: 345-354.

39. Tan Z Y, Xu X D, Wang E T, Gao J L, Martinez-Romero E, Chen W $\mathrm{X}$. Phylogenetic and genetic relationships of Mesorhizobium tianshanense and related rhizobia. International Journal of Systematic Bacteriology. 1997; 47: 874-879.

40. Tindall B J, Rosselló-Móra R, Busse H-J, Ludwig W, Kämpfer P. Notes on the characterization of prokaryote strains for taxonomic purposes. International Journal of Systematic and Evolutionary Microbiology. 2010; 60: 249-266.

41. Zhang J J, Liu T Y, Chen W F, Wang E T, Sui X H, Zhang X X, et al. Mesorhizobium muleiense sp nov, nodulating with Cicer arietinum $L$. International Journal of Systematic and Evolutionary Microbiology. 2012; 62: 2737-2742.

42. Lupski J R, Weinstock G M. Short, interspersed repetitive repetitive DNA sequences in prokaryotic genome. Journal of bacteriology. 1992; 174:4525-4529.

43. Woese C R, Bacterial evolution. Microbiological Reviews. 1987; 51(2): 221-271.

44. Dubnau D, Smith I, Morell P, Marmur J. Gene conservation in Bacillus species I conserved genetic and nucleic acid base sequence homologies. Proceedings of National Academy of Science United States of America. 1965; 54:491-498.

45. Clarridge J E. Impact of $16 \mathrm{~S}$ rRNA gene sequence analysis for identification of bacteria on clinical microbiology and infectious diseases. Clinical Microbiology Reviews. 2004; 17: 840- 862.

46. Nour S M, Cleyet-Marel J C, Normand P, Fernandez M P. Genomic heterogeneity of strains nodulating chickpea (Cicer arietinum L.) and description of Rhizobium mediterraneum sp. nov. International Journal of Systematic and Evolutionary Bacteriology.1995; 45: 640-648.

47. Chaudhary P, Dudeja S S, Khurana A L. Chickpea nodulation variants as a tool to detect the population diversity of chickpea rhizobia in soil. Physiology and Molecular Biology of Plants. 2001; 7: 47-54.

48. Laranjo M, Rodrigues R, Alho L, Oliveria S. Rhizobia of chickpea from Southern Portugal: Symbiotic efficiency and genetic diversity. Journal of Applied Microbiology. 2001; 90: 662-667.

49. Laranjo M, Branco C, Soares R, Alho L, Carvalho M D, Oliveria S. Comparison of chickpea rhizobia isolated from diverse Portuguese natural populations based on symbiotic effectiveness and DNA fingerprinting. Journal of Applied Microbiology. 2002; 92: 1043-1050.

50. Laranjo M, Machado J, Young J P W, Oliveira S. High diversity of chickpea Mesorhizobium species isolated in a Portuguese agricultural region. FEMS Microbiology Ecology. 2004; 48: 101-107.

51. Maatallah J, Berraho E B, Munoz S, Sanjuan J, Lluch C. Phenotypic and molecular characterization of chickpea rhizobia isolated from different areas of Morocco. Journal of Applied Microbiology. 2002; 93: 531-540.

52. L'taief B, Sifi B, Gtari M, Zaman-Allah M, Lachaâl M. Phenotypic and molecular characterization of chickpea rhizobia isolated from different areas of Tunisia. Canadian Journal of Microbiology. 2007; 53(3):427-34.

53. Alexandre A, Brigido C, Laranjo M, Rodrigues S, Oliveira S. Survey of chickpea rhizobia diversity in Portugal reveals the predominance of species distinct from Mesorhizobium ciceri and Mesorhizobium mediterraneum. Microbial Ecology. 2009; 58: 930-941.

54. Asgharzadeh A, Rafiee M, Kargar M, Asadi Rahmani H. Genetic diversity of chickpea- nodulating Mesorhizobium species native to Irania soils. Iraninan Journal of Soil Research.2013; 27(1): 121-129.

55. Rai R, Dash P K, Trilochan M, Singh A. Phenotypic and molecular characterization of indigenous rhizobia nodulating chickpea in India. Indian Journal of Experimental Biology. 2012; 50: 340-350.

56. Alexandre A, Laranjo M, Oliveira S. Natural populations of chickpea rhizobia evaluated by antibiotic resistance profiles and molecular methods. Microbial Ecology. 2006; 51(1): 128-136.

57. Rivas R, Laranjo M, Mateos P F, Oliveira S, Martinez-Molina E, Velazquez E. Strains of Mesorhizobium amorphae and Mesorhizobium tianshanense, carrying symbiotic genes of common chickpea endosymbiotic species, constitute a novel biovar (ciceri) capable of nodulating Cicer arietinum, Letters in Applied Microbiology. 2007; 44: 412-418.

58. Laranjo M, Alexandre A, Rivas R, Velazquez E, Young J P, Oliveira S. Chickpea rhizobia symbiosis genes are highly conserved across multiple Mesorhizobium species. FEMS Microbiology Ecology. 2008; 66: 391-400.

59. Zhang J J, Yu T, Lou K, Mao P H, Wang E T, Chen W F. Genotypic alteration and competitive nodulation of Mesorhizobium muleiense against exotic chickpea rhizobia in alkaline soils. Systematic and Applied Microbiology. 2014; 37(7): 520-524.

60. Peix A, Ramírez-Bahena M H, Velázquez E and Bedmar E J. Bacterial Associations with Legumes. Critical Reviews in Plant Sciences .2015; 34:1-3, 17-42, DOI: 10.1080/07352689.2014.897899.

61. Jordan D C. Transfer of Rhizobium japonicum Buchanan 1980 to Bradyrhizobium gen. nov., a genus of slow-growing, root nodule bacteria from leguminous plants. International Journal of Systematic Bacteriology. 1982; 32: 136-139.

62. Young J P W, Crossman L, Johnston A, et al. The genome of Rhizobium leguminosarum has recognizable core and accessory components. Genome Biology. 2006; 7: R34. 
63. Rogel M A, Ormeno-Orrillo E, Martinez Romero E. Symbiovars in rhizobia reflect bacterial adaptation to legumes. Systematic and Applied Microbiology. 2011; 34: 96-104.

64. Berrada H, Fikri-Benbrahim K. Taxonomy of the Rhizobia: current perspectives. British Microbiology Research Journal. 2014; 4(6): 616639.

65. Laranjo M, Young J P W, Oliveria S. Multilocus sequence analysis reveals multiple symbiovars within Mesorhizobium species. Systematic and Applied Micobiology. 2012; 35: 359-367.

66. Thrall P H, Murray B R, Watkin E, Woods M, Baker K, Burdon J J, Brockwell J. Bacterial partnerships enhance the value of native legumes in revegetation and rehabilitation of degraded agricultural lands. Ecology Management Restoration, Malden. 2001; 2: 233-235.

67. Kim D H, Kaashyap M, Rathore A, Das R R, Parupalli S, Upadhyaya H D, Gopalakrishnan S, Gaur P M, Singh S, Kaur J, Yasin M, Varshney R K. Phylogenetic diversity of Mesorhizobium in chickpea. Journal of Biosciences. 2014; 39(3): 513-517.

68. Armas-Capote N, Perez-Yepez J, Martinez-Hidalgo P, GarzonMachado V, Del Arco-Aguilar M, Velazquez E, Leon-Barrios M. Core and symbiotic genes reveal nine Mesorhizobium genospecies and three symbiotic lineages among the rhizobia nodulating Cicer canariense in its natural habitat (La Palma, Canary Islands). Systematic and Applied Microbiology. 2014; 37: 140-148.

69. Prakash O, Verma M, Sharma P, Kumar M, Kumari K, Singh A, Kumari H, Jit S, Gupta S K, Khanna M, Lal R. Polyphasic approach of bacterial classification- An overview of recent advances. Indian Journal of Microbiology.2007; 47: 98-108.
70. Greenspan A, Kim D H,Chang P, Khan A W, Bergmann E M, Sanchez V,Vance L, Scharnagl K, Kaashyap, M, Yasin M, Kaur Singh S, Upadhyaya H D , Gaur P M, Penmesta R V, Wettberg E V, Varshney R K, Cook D R . 2014; The impact of domestication on nitrogen fixation in chickpea: parrallel shifts in bacterial genome structure and host selectivity, Plant Animal Genome XII, AgGenomics Meeting.

\section{How to cite this article:}

Suneja P, Dudeja SS, Dahiya P. Deciphering the phylogenetic relationships among rhizobia nodulating chickpea: A Review. J App Biol Biotech. 2016; 4 (03): 061-070. DOI: 10.7324/JABB.2016.40310 